\title{
The HNF1a-regulated IncRNA HNF1A-AS1 reverses the malignancy of hepatocellular carcinoma by enhancing the phosphatase activity of SHP-1
}

Chen-Hong Ding ${ }^{1 \dagger}$, Chuan Yin ${ }^{1 \dagger}$, Shi-Jie Chen ${ }^{2 \dagger}$, Liang-Zhi Wen ${ }^{1,3}$, Kai Ding $^{1}$, Shu-Juan Lei ${ }^{1}$, Jin-Pei Liu ${ }^{1}$, Jian Wang ${ }^{1}$, Kai-xian Chen ${ }^{2}$, Hua-liang Jiang ${ }^{2}$, Xin Zhang ${ }^{1}$, Cheng Luo ${ }^{2^{*}}$ and Wei-Fen Xie ${ }^{1 *}$

\begin{abstract}
Background: Our previous study has demonstrated that hepatocyte nuclear factor 1a (HNF1a) exerts potent therapeutic effects on hepatocellular carcinoma (HCC). However, the molecular mechanisms by which HNF1a reverses HCC malignancy need to be further elucidated.

Methods: IncRNA microarray was performed to identify the long noncoding RNAs (IncRNAs) regulated by HNF1a. Chromatin immunoprecipitation and luciferase reporter assays were applied to clarify the mechanism of the transcriptional regulation of HNF1a to HNF1A antisense RNA 1 (HNF1A-AS1). The effect of HNF1A-AS1 on HCC malignancy was evaluated in vitro and in vivo. RNA pulldown, RNA-binding protein immunoprecipitation and the Bio-Layer Interferometry assay were used to validate the interaction of HNF1A-AS1 and Src homology region 2 domain-containing phosphatase 1 (SHP-1).

Results: HNF1a regulated the expression of a subset of IncRNAs in HCC cells. Among these IncRNAs, the expression levels of HNF1A-AS1 were notably correlated with HNF1a levels in HCC cells and human HCC tissues. HNF1a activated the transcription of HNF1A-AS1 by directly binding to its promoter region. HNF1A-AS1 inhibited the growth and the metastasis of HCC cells in vitro and in vivo. Moreover, knockdown of HNF1A-AS1 reversed the suppressive effects of HNF1a on the migration and invasion of HCC cells. Importantly, HNF1A-AS1 directly bound to the C-terminal of SHP-1 with a high binding affinity (KD $=59.57 \pm 14.29 \mathrm{nM})$ and increased the phosphatase activity of SHP-1. Inhibition of SHP-1 enzymatic activity substantially reversed the HNF1a- or HNF1A-AS1-induced reduction on the metastatic property of HCC cells.
\end{abstract}

Conclusions: Our data revealed that HNF1A-AS1 is a direct transactivation target of HNF1a in HCC cells and involved in the anti-HCC effect of HNF1a. HNF1A-AS1 functions as phosphatase activator through the direct interaction with SHP-1. These findings suggest that regulation of the HNF1a/HNF1A-AS1/SHP-1 axis may have beneficial effects in the treatment of HCC.

Keywords: HNF1a, HNF1A-AS1, Hepatocellular carcinoma, SHP-1, phosphatase activity

\footnotetext{
*Correspondence: cluo@simm.ac.cn; weifenxie@medmail.com.cn

${ }^{\dagger}$ Equal contributors

${ }^{2}$ Drug Discovery and Design Center, CAS Key Laboratory of Receptor

Research, State Key Laboratory of Drug Research, Shanghai Institute of

Materia Medica, Chinese Academy of Sciences (CAS), Shanghai 201203, China

'Department of Gastroenterology, Changzheng Hospital, Second Military

Medical University, 415 Fengyang Road, Shanghai 200003, China

Full list of author information is available at the end of the article
} 


\section{Background}

Hepatocellular carcinoma (HCC) is one of the most common cancers and the second leading cause of cancer mortality worldwide [1]. Recently, accumulating evidences have demonstrated that long non-coding RNAs (lncRNAs), a large class of transcripts longer than 200 nucleotides (nt) without protein-coding potentials, are closely associated with the occurrence and development of human cancers, including HCC [2-5] .

Hepatocyte nuclear factor $1 \alpha$ (HNF1 $\alpha)$, a POUhomeodomain family transcription factor, expressed predominantly in the liver, and it regulates many aspects of hepatocyte functions [6-8]. We have previously reported that the enforced expression of HNF1 $\alpha$ impedes the growth of HCC xenografts in mice by inducing the differentiation of hepatoma cells into hepatocytes [9]. Our recent study further demonstrated that hepatocyte-specific Hnfl $\alpha$ knockout mice spontaneously develop HCC from fatty liver without cirrhosis [10]. In addition, it has been reported that HNF1 $\alpha$ inhibits Wnt and NF- $\mathrm{kB}$ signalling during hepatocarcinogenesis and HCC metastasis by transcriptionally regulating the expression of miR-194 [11, 12]. However, whether lncRNAs contribute to the suppressive effect of HNF1 $\alpha$ on HCC remains unclear.

Src homology region 2 (SH2) domain-containing phosphatase 1 (SHP-1, also known as PTPN6), a nonreceptor protein tyrosine phosphatase (PTP), is predominantly expressed in haematopoietic and epithelial cell and widely accepted as a negative regulator of inflammation and as a tumour suppressor $[13,14]$. SHP-1 plays a crucial role in glucose homeostasis and lipid metabolism in the liver [15-17]. Previous studies indicated that sorafenib, a multi-kinase inhibitor approved for HCC treatment, increased the activity of SHP-1 in HCC [18-20]. SHP-1 also repressed TGF- $\beta$-induced EMT and further inhibited the migration and invasion of HCC cells [21]. Our recent study revealed that HNF1 $\alpha$ inhibits liver fibrosis by regulating SHP-1 expression in rat hepatocytes [22]. Therefore, it is of interest to clarify the role of SHP-1 in anti-tumour effect of HNF1 $\alpha$.

In this study, we reported that HNF1A-AS1, an lncRNA found only in primates, was transcriptionally activated by HNF1 $\alpha$ in human HCC cells. HNF1A-AS1 inhibited the malignant properties of HCC cells both in vitro and in vivo and contributed to the anti-tumour effects of HNF1 $\alpha$. Importantly, we found that HNF1AAS1 mediated the regulation of HNF1 $\alpha$ on SHP-1 activity in HCC cells and increased the phosphatase activity of SHP-1 by directly binding to the C-terminal of SHP1. Blocking the SHP-1 activity reverse the anti-HCC effect of HNF1 $\alpha$ and HNF1A-AS1. These findings suggested that HNF1A-AS1 exerts its suppressing effect on $\mathrm{HCC}$ through direct regulating the enzyme activity of SHP-1.

\section{Methods}

\section{Viruses}

To generate lentiviruses for the overexpression of HNF1 $\alpha$ and HNF1A-AS1, full-length cDNA of HNF1 $\alpha$ and HNF1A-AS1 were cloned into the pCDH-CMV-MCSEF1-copGFP vector (System Biosciences). For HNF1 $\alpha$ targeting short hairpin RNA expression, oligonucleotides encoding HNF1 $\alpha$ short hairpin RNA (GATCCGGTCTTCACCTCAGACACTTTC AAGAGAAGTGTCTGAGGT GAAGACCTTTTTG) were cloned into the pmiRZIP vector (System Biosciences). All vectors were verified by sequencing. The primer sequences are listed in Additional file 1: Table S1.

The lentiviral vectors were transfected into subconfluent HEK293T cells together with the packaging plasmid psPAX2 and envelope plasmid pMD2.G (Addgene) using FuGENE 6 transfection reagent (Promega) to produce lentiviral particles. The lentiviruses in the medium were collected $48 \mathrm{~h}$ later and concentrated by ultracentrifugation.

\section{Cell culture}

The human HCC cell lines Huh-7, MHCC-97 L, MHCC97H, MHCC-LM3, SMMC-7721 and YY-8103 were obtained from Type Culture Collection of the Chinese Academy of Sciences (Shanghai, China). HepG2, Hep3B, PLC/PRF/5 and $293 \mathrm{~T}$ cells were from American Type Culture Collection. HepG2 and Hep3B cells were cultured in Eagle's minimum essential medium (MEM) supplemented with $10 \%$ FBS and $1 \times$ nonessential amino acid (NEAA). The other cells were cultured in Dulbecco's modified Eagle's medium (DMEM) supplemented with 10\% FBS.

\section{Microarray analysis}

Total RNA was extracted from Huh-7 cells infected with Lenti-HNF1 $\alpha$, Lenti-shHNF1 $\alpha$ and their corresponding control viruses and subjected to hybridization on an Agilent Human $180 \mathrm{~K}$ lncRNA microarray v4.0 (Agilent, Santa Clara, CA, USA) according to the manufacturer's instructions. Images of hybridized microarrays were scanned using an Agilent Scanner (Agilent), and the raw data were normalized using a quantile algorithm, Gene Spring Software 11.0 (Agilent). Microarray hybridization, scanning and analysis were performed by Shanghai Biotechnology Corporation (Shanghai, China). The differentially expressed lncRNAs were acquired according to the significance of a false discovery rate (FDR) at 5\% and a fold-change (FC) cut-off at 2 . The entire dataset is available at NCBI Gene Expression Omnibus (http:// www.ncbi.nlm.nih.gov/geo/) under the accession number GSE103128.

\section{Human tissues}

All human HCC samples were obtained from $\mathrm{HCC}$ patients undergoing surgical resection at the Eastern 
Hepatobiliary Surgery Hospital (Shanghai, China). Written informed consent was obtained from all patients. All human experiments were approved by the Ethics Committee of the Second Military Medical University (Shanghai, China).

\section{Total RNA isolation and real-time polymerase chain reaction} (RT-PCR)

Total RNA was isolated from cells or tissues with readyto-use TRIzol Reagent (TaKaRa). SuperScript III reverse transcriptase (Invitrogen) was employed to synthetize first-strand cDNA. Real-time PCR was performed in an ABI StepOne Real-time Detection System (Life Technologies) using SYBR Green (Takara). The primer sequences are listed in Additional file 1: Table S1.

\section{Western blotting analysis}

Proteins were extracted using RIPA buffer (P0013B, Beyotime, Suzhou, China) supplemented with protease inhibitor cocktail (Roche), separated via sodium dodecylsulfate-polyacrylamide gel electrophoresis (SDSPAGE), and transferred to NC membranes (HAHY00010, Millipore). The membranes were blocked in PBS-T containing 5\% skim milk or BSA for $2 \mathrm{~h}$ and then incubated with primary antibodies overnight at $4{ }^{\circ} \mathrm{C}$. After $2 \mathrm{~h}$ of incubation with secondary antibody (donkey anti-mouse or donkey anti-rabbit, IRDye 700 or IRDye 800), signals were detected using an Odyssey Infrared Imaging System (LI-COR) at 700 or $800 \mathrm{~nm}$.

\section{Northern blotting and rapid amplification of CDNA ends (RACE)}

Northern blotting for HNF1A-AS1 was performed on purified polyA+ RNA using biotin-labelled probes. Briefly, polyA+ RNA was purified using the Dynabeads ${ }^{\circ}$ mRNA DIRECT Purification Kit (Thermo Fisher). Then, $10 \mu \mathrm{g}$ polyA+ RNA was electrophoresed and transferred to a positively charged Biodyne B Nylon Membrane (Pall, P/N 60200). The transferred RNA was then fixed to the nylon membrane using UV cross-linking. RNA was detected with a specific oligonucleotide probe representing HNF1A-AS1 labelled with biotin-16-dUTP (Roche). Human Liver Marathon-Ready cDNA (Clontech) was used to perform $3^{\prime}$ and $5^{\prime}$ RACE according to the manufacturer's instructions. All the primer sequences are listed in Additional file 1: Table S1.

\section{Chromatin immunoprecipitation (ChIP) assay}

Huh-7 cells were cross-linked and sonicated to shear DNA to an average fragment size of 200 to $1000 \mathrm{bp}$. For endogenous chromatin immunoprecipitation, the chromatin fragments were immunoprecipitated using $10 \mu \mathrm{g}$ anti-HNF1 $\alpha$ antibodies (sc-10,791, Santa Cruz). Normal rabbit IgG was used as a negative control. For chromatin immunoprecipitation using ectopic HNF1 $\alpha$, chromatin fragments derived from Huh-7 cells transfected with Flag-HNF1 $\alpha$ or Flag-CMV-2 were immunoprecipitated with anti-FLAG Ab-conjugated agarose beads (A2220; Sigma-Aldrich, St. Louis, MO). DNA extraction was performed using Qiagen Purification Kits. Real-time PCR analysis was carried out to detect HNF1 $\alpha$ binding sites on the HNF1A-AS1 promoter. OCT1 was used as a positive control. The primer sequences for ChIP-PCR are shown in Additional file 1: Table S1.

\section{Luciferase reporter assay}

To test the transcriptional activity of HNF1 $\alpha$ on the HNF1A-AS1 promoter, an HNF1A-AS1 promoter fragment containing the HNF1 $\alpha$ response element (RE) was amplified by PCR from genomic DNA and cloned into the pGL3-Promoter vector (E1761, Promega). The HNF1 $\alpha$-RE was mutated using the Hieff MutSite-Directed Mutagenesis Kit (Yeasen Biotechnology, Shanghai, China). Huh-7 cells pre-infected with Lenti-HNF1 $\alpha$ for $24 \mathrm{~h}$ were cotransfected with HNF1 $\alpha$-RE-LUC vectors together with the control pRL-SV40 vector (E2261, Promega). Luciferase activity was measured using the Dual-Glo Luciferase Assay System (E2920, Promega) $48 \mathrm{~h}$ post-transfection. All constructs were verified by DNA sequencing. The primer sequences for the constructs are listed in Additional file 1: Table S1. At least three independent transfection experiments were carried out for each condition.

\section{Cell proliferation, colony formation, and soft agar colony formation assay}

HCC cells were infected with lentiviruses and adenoviruses or transfected with siRNAs for $8-12 \mathrm{~h}$ and then plated in 96-well plates at the density of 3000 cells per well with $100 \mu \mathrm{l}$ of complete culture medium. Cell proliferation was examined by the Cell Counting Kit- 8 (Dojindo, Tokyo, Japan) according to the manufacturer's instructions. For colony formation assays in culture plates, HCC cells infected or transfected for 24-48 h were seeded on $60 \mathrm{~mm}$ dishes. For soft agar colony formation assays, HCC cells infected or transfected for 24$48 \mathrm{~h}$ were resuspended in medium containing $0.5 \%$ low melting point agarose and seeded in plates containing medium with $1 \%$ solidified agarose. After 2 to 3 weeks, colonies on plates or in soft agar were stained with $0.1 \%$ crystal violet, photographed and counted. At least three independent experiments were performed for each condition.

\section{In vitro migration and invasion assay}

In vitro migration and invasion assays were performed as described previously [23]. To investigate the effect of SHP-1 on the role of HNF1 $\alpha$ and HNF1A-AS1 in HCC cells, $15 \mu \mathrm{M} / \mathrm{L}$ PTP inhibitor III (Merck Millipore) was 
added to the medium, and DMSO was used as control. After incubation for $24-48 \mathrm{~h}$ at $37{ }^{\circ} \mathrm{C}$, the cells were fixed and stained as previously described [23]. Image analysis software (Image-Pro Plus 6.0, Media Cybernetics) was used to measure the area of positive staining.

\section{Animal models}

Male BALB/c nude mice (5 6 weeks old) or NOD/SCID mice (5 6 weeks old) were purchased from Shanghai Experimental Animal Center of the Chinese Academy of Sciences, Shanghai, China. To detect the effect of HNF1A-AS1 on the tumourigenicity of HCC cells, $2 \times$ $10^{6}$ Huh-7 or $1 \times 10^{6}$ MHCC-LM3 cells pre-infected with Lenti-HNF1A-AS1 or control virus were subcutaneously injected into flanks of BALB/c nude mice. Tumour formation was estimated as previously described [24]. MHCC-LM3 cells stably expressing luciferase and infected with Lenti-HNF1A-AS1 or control virus were injected via the tail veins into NOD/SCID mice to generate a tumour metastasis model. Mice were monitored using the IVIS 200 imaging system (Caliper Life Sciences, Hopkinton, MA) once per week and sacrificed 6 weeks after injection. Metastatic tumour nodules in different organs of the mice were further monitored using in vivo luciferase assays [25]. All animal experiments were performed in accordance with protocols approved by the Institutional Animal Care and Use Committee at the Second Military Medical University, Shanghai, China.

\section{Protein recombination and purification}

Recombinant His-SHP-1, GST-SHP-1 and GST-SHP-1 variants were expressed using pET28a or pGEX4T-1 expression vectors in Escherichia coli. Recombinant His-SHP-1 was purified using a nickel affinity chromatography column (5 mL HisTrap FF, GE Healthcare). GST-SHP-1 and GST-SHP-1 variants were purified with Glutathione SepharoseTM 4B-beads (GE Healthcare).

\section{RNA immunoprecipitation (RIP) assay}

RNA-binding protein immunoprecipitation (RIP) assays were performed as previously described with minor modifications [24]. Briefly, primary antibody against SHP-1 (sc-287 Santa Cruz) was used to immuneprecipitate the endogenous SHP-1; anti-FLAG Ab-conjugated agarose beads (Sigma-Aldrich) were used for immuneprecipitating Flag-SHP-1 in Huh-7 cells transfected with pFlag-CMV-SHP-1 or Flag-CMV-SHP-1 $\Delta 517-597$.

\section{RNA pulldown assay}

Biotin-labelled RNA was transcribed in vitro with the Biotin RNA Labelling Mix (Roche) and T7 RNA polymerase (Ambion) and purified using the RNeasy Mini Kit (ZOMY). To allow proper secondary structure formation, biotinylated RNA in RNA structure buffer
(10 mM Tris $\mathrm{pH}=7.0,0.1 \mathrm{M} \mathrm{KCl}, 10 \mathrm{mM} \mathrm{MgCl}$ ) were heated to $90{ }^{\circ} \mathrm{C}$ for $2 \mathrm{~min}$, put on ice for $3 \mathrm{~min}$, and left at room temperature (RT) for $30 \mathrm{~min}$. The folded RNA was mixed with $1 \mathrm{mg}$ Huh-7 cell lysate or $1 \mu \mathrm{g}$ recombinant His-SHP-1 in $500 \mu \mathrm{l}$ RIP buffer and incubated at RT for one hour. The RNA-protein complexes were captured with $25 \mu \mathrm{l}$ washed streptavidin agarose beads (Invitrogen) at RT for one hour. The beads were briefly washed five times with RIP buffer $(50 \mathrm{mM}$ Tris $\mathrm{pH}=7.4$, $150 \mathrm{mM} \mathrm{NaCl}, 2 \mathrm{mM} \mathrm{MgCl}, 0.5 \% \mathrm{NP} 40$ ) and boiled in SDS buffer. The retrieved proteins were detected by western blotting.

\section{Bio-layer interferometry (BLI) assay}

A ForteBio Octet ${ }^{\circledR}$ K2 System (Pall) was used to measure the binding kinetics of HNF1A-AS1 with purified HisSHP1. All of the assays were performed at $30{ }^{\circ} \mathrm{C}$ in opaque flat-bottom 96-well plates (Greiner), with agitation set to $1000 \mathrm{rpm}$ in DEPC-treated PBS $(\mathrm{pH}=7.4)$ supplemented with $0.01 \%$ Tween-20 to minimize nonspecific interactions. Biotinylated HNF1A-AS1 (100 nM) in PBS-Tween were immobilized on super streptavidincoated biosensors (Pall) for 300 s. The biosensor tips were equilibrated in buffer for $600 \mathrm{~s}$ prior to binding purified His-SHP1 and His-SHP1 $\triangle 517-597$ at increasing concentrations $(0 \mathrm{nM}, 31.25 \mathrm{nM}, 62.5 \mathrm{nM}, 125 \mathrm{nM}$, $250 \mathrm{nM}$, and $500 \mathrm{nM}$ ) for $300 \mathrm{~s}$. The complex was allowed to dissociate in PBS-Tween for $600 \mathrm{~s}$. Data were analysed using Octet software, version 9.0 (Pall). An empty sensor was used to bind protein at high concentration $(1000 \mathrm{nM})$ as the negative control. Experimental data were fitted into binding equations describing a 1:1 interaction. Global analyses of the datasets assuming that binding was reversible (full dissociation) were carried out using nonlinear least-squares fitting, allowing a single set of binding parameters to be simultaneously obtained for all concentrations used in each experiment.

\section{Phosphatase assay}

A RediPlate 96 EnzChek $^{\circ}$ Tyrosine Phosphatase Assay Kit (R-22067) was used for SHP-1 activity assay (Molecular Probes, Invitrogen, CA). To detect the phosphatase activity of endogenous SHP-1, SHP-1 protein in Huh-7 cell lysates was incubated with anti-SHP-1 antibody at $4{ }^{\circ} \mathrm{C}$ overnight and precipitated with Protein G-Agarose beads (Roche). The beads were washed with immunoprecipitation buffer (20 mM Tris- $\mathrm{HCl}(\mathrm{pH} 8.0)$, $50 \mathrm{mM} \mathrm{NaCl}, 0.5 \%$ Triton-X-100, and $10 \%$ glycerol) and placed into RediPlate wells. SHP-1 activity was measured at 360/40 and $460 / 40 \mathrm{~nm}$. The amount of SHP-1 protein used for the phosphatase assay were evaluated by western blotting. For in vitro phosphatase assay, $4 \mathrm{nM}$ recombinant His-SHP-1 or His-SHP-1 $\Delta 517-597$ protein and $4 \mathrm{nM}$ 
HNF1A-AS1 were added into RediPlate wells and incubated for $30 \mathrm{~min}$ at RT before reading fluorescence.

\section{Statistical analysis}

Data analyses were performed with Prism 5 (GraphPad software, La Jolla, CA). For experiments involving only two groups, data were analysed with Student's unpaired $t$ tests. All data are presented as the mean \pm SD. Statistical significance was set at ${ }^{*} P \leq 0.05,{ }^{* *} P \leq 0.01$, and ${ }^{* * * *} P \leq$ 0.001. $P \leq 0.05$ was considered statistically significant.

\section{Results}

HNF1a regulates the expression of HNF1A-AS1

To identify the lncRNAs regulated by HNF1 $\alpha$, we conducted two sets of microarray analyses to obtain lncRNA expression profiles in Huh-7 cells in which HNF1 $\alpha$ was either up- or down-regulated (Fig. 1a and Additional file 1: Figure S1a). We found that overexpression of HNF1 $\alpha$ resulted in the upregulation of 2323 lncRNAs and the downregulation of 2713 lncRNAs in Huh-7 cells (Additional file 1: Figure S1b). In contrast, knockdown of HNF1 $\alpha$ led to the increased expression of 2455 lncRNAs

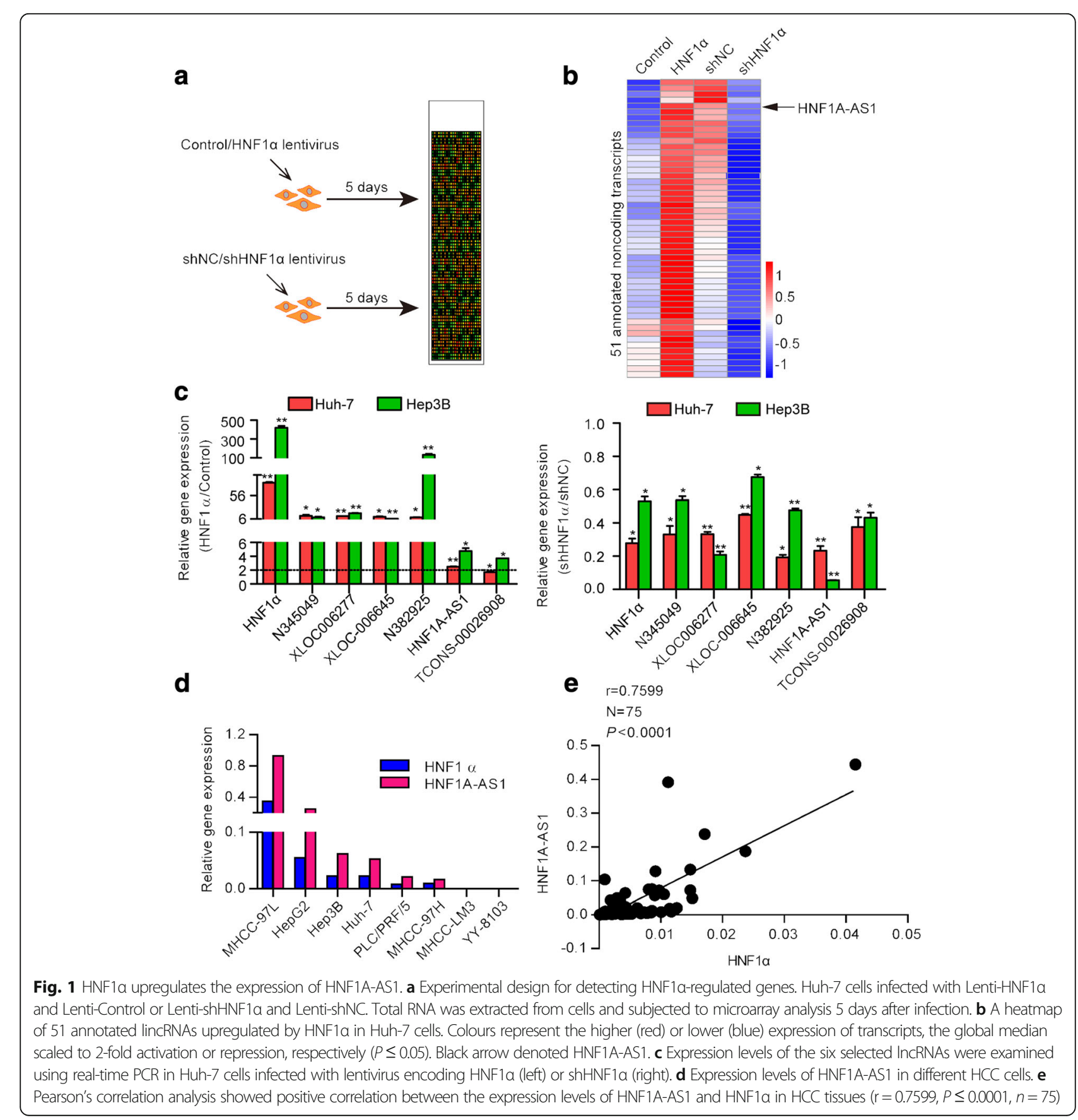


and the decreased expression of 2683 lncRNAs (Additional file 1: Figure S1b). Overlapping the two sets of data revealed that 443 lncRNAs were upregulated and 450 lncRNAs were downregulated by HNF1 $\alpha$ in Huh-7 cells (Additional file 1: Figure S1c).

As HNF1 $\alpha$ is a transactivation factor in hepatocytes, we selected 51 annotated lncRNAs from the 443 HNF1 $\alpha$-upregulated IncRNAs and analysed their promoters (Fig. 1b and Additional file 2: Table S2). Six long intergenic non-coding RNAs (lincRNAs) containing putative HNF1 $\alpha$-REs in their promoters were selected as the potential targets of HNF1 $\alpha$ (Additional file 1: Table S3). Real-time PCR confirmed that HNF1 $\alpha$ elevated the levels of these lincRNAs in HCC cells (Fig. 1c). Among these six lincRNAs, the expression level of HNF1A-AS1 was remarkably correlated with HNF1 $\alpha$ expression in HCC cells (Fig. 1d, Additional file 1: Figure S1d and e).
Moreover, a significantly positive correlation between HNF1 $\alpha$ and HNF1A-AS1 was also detected in human HCC samples (Fig. 1e). We then analysed the characteristics of HNF1A-AS1 and further investigated the regulatory effect of HNF1 $\alpha$ on HNF1A-AS1 in HCC cells.

\section{HNF1a activates the transcription of HNF1A-AS1}

The HNF1A-AS1 gene is located on human chromosome $12 \mathrm{q} 24.31$ and approximately $6 \mathrm{~kb}$ away from the HNF1 $\alpha$ gene. It had been reported that HNF1A-AS1 is transcribed as a $2455 \mathrm{nt}$ lncRNA in the opposite direction to the HNF1 $\alpha$ gene. However, northern blotting indicated that HNF1A-AS1 is longer than 2600 nt in human hepatoma cells (Fig. 2a). We then performed 5' rapid amplification of cDNA ends (5' RACE) and 3' RACE to amplify HNF1A-AS1 transcripts in a human liver cDNA library. Sequencing of PCR products

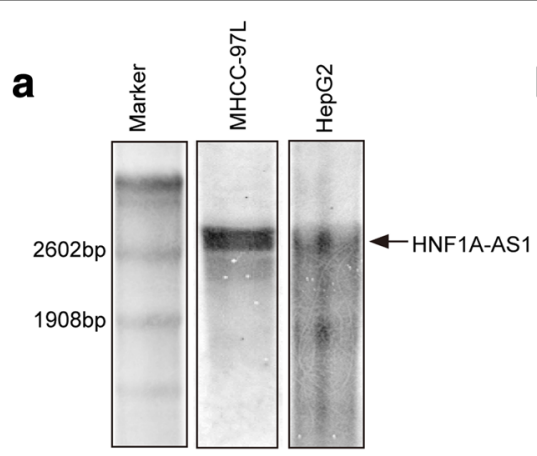

b GGAACAGCCGGACATGGTAGCTCATACCTGTAATCCCAG CGCTTTGGGAGACCGAGGCAGGTGGATCACCTGAGGTC AGGAGTTCCAGATCAGCCTGGCCAACATGGTAAAACCCC ATCTCTACTAAAAATACAAAAATTAGCTGGATGTGGTGGC GCACACCTGTAGTCCCAGATACTCAGGAGGCTGAGGCAG GAGAATAGCTTGAACCCGGGAGGCGGAGGTTGCAGTGA GCAGAGATCACGCCACTGCACTCCAGCCTGGGCGATAG AGTAACAATCCGTCTCAAAAAAATCTGAAAATTAAAAATTA AAAAGTGAACAGTTGTTTAGTAAGTGCAGTAGGTAGGCCA AGATAACTATTAAGTATTTCCTAACAAGGTA

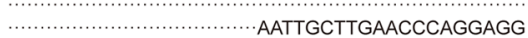
CGGGGGTTGCAGTGAGTCGAGATCGCCCCATTGTACTCC AGCCTGGGGAACAAGAACGAAACTCCGTCTC

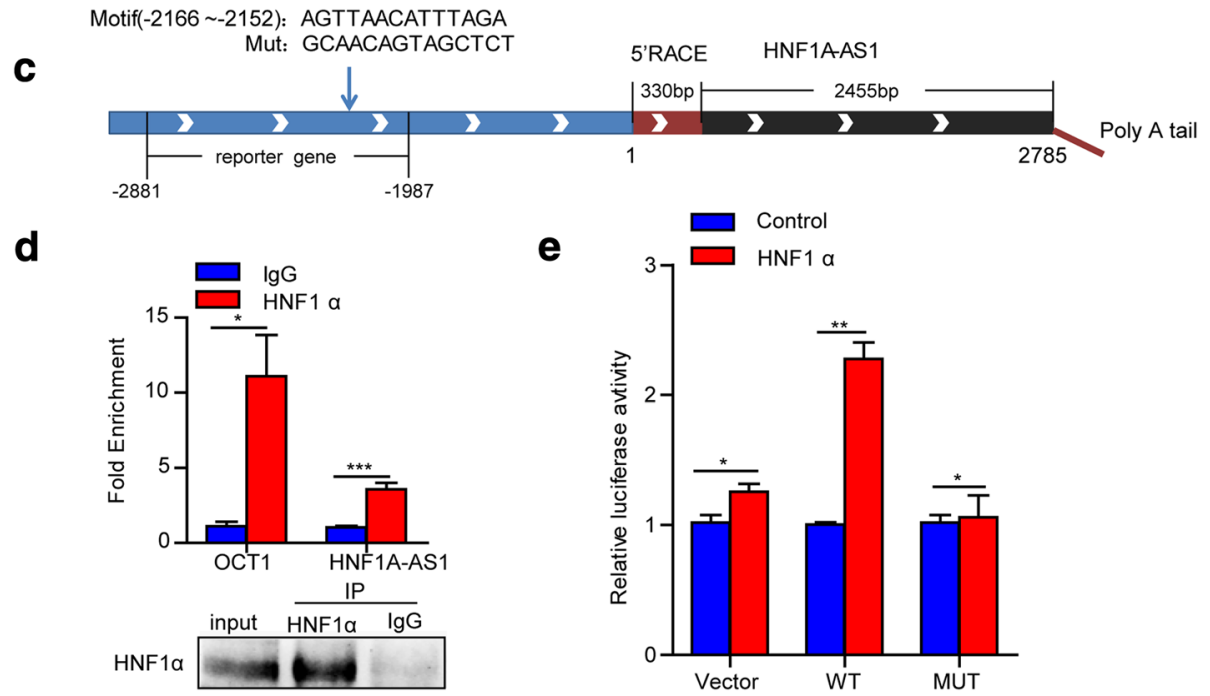

Fig. 2 HNF1 a activates the transcription of HNF1A-AS1 by directly binding to its promoter. a Northern blotting was performed to verify the expression of HNF1A-AS1 in MHCC-L and HepG2 cells. b Sequence of full-length human HNF1A-AS1 in the liver. Nucleotides identified by RACE are indicated in red. c Schematic representation of the full-length HNF1A-AS1 gene, the predicted HNF1a-RE in the promoter region, the mutated sequence of HNF1aRE and the fragment for the reporter plasmid. $\mathbf{d}$ ChIP assays revealed the binding of HNF1a to the promoter region of HNF1A-AS1. Real-time PCR (upper panel) was performed to examine DNA fragments immunoprecipitated by anti-HNF1a antibody in Huh-7 cells. Western blotting (lower panel) was used to verify the immunoprecipitation of the HNF1a protein. Human OCT1 promoter containing a consensus HNF1a response element was used as the positive control. e Luciferase reporter assays performed with a reporter plasmid carrying the HNF1a-RE in Huh-7 cells co-transfected with Flag-CMV or Flag-HNF1a. Mutation of HNF1a-RE abolished the transcriptional activity of HNF1a. Data represent the mean \pm SD. ${ }^{*} P \leq 0.05$, ${ }^{* *} P \leq 0.01$, and ${ }^{* * *} P \leq 0.001$ 
revealed that the full-length transcript of HNF1A-AS1 RNA is 2785 nt with a poly A tail, which is $330 \mathrm{nt}$ longer at the $5^{\prime}$ end than the previously published sequence of HNF1A-AS1 in the NCBI database (Fig. 2b).

According to the JASPAR database [26], a putative HNF1 $\alpha-R E$ is located 2166 to 2152 bp upstream of the HNF1A-AS1 transcriptional start site (Fig. 2c). ChIP assays confirmed the direct binding of HNF1 $\alpha$ to the promoter of HNF1A-AS1 (Fig. 2d, and Additional file 1: Figure S2a-c). Luciferase reporter assays also showed that the ectopic expression of HNF1 $\alpha$ increased the transcriptional activity of the HNF1A-AS1 promoter, which was impaired by mutations in the HNF1 $\alpha$-RE (Fig. 2e). Taken together, these data suggested that HNF1 $\alpha$ regulates HNF1A-AS1 by directly binding to its promoter region.

\section{HNF1A-AS1 suppresses the malignant properties of HCC cells}

To evaluate the potential role of HNF1A-AS1 in HCC, we modulated its expression in HCC cells. The enforced expression of HNF1A-AS1 by lentiviral infection notably suppressed HCC cell growth (Fig. 3a and Additional file 1: Figure S3a), whereas reduced HNF1A-AS1 expression via siRNA promoted the proliferation of $\mathrm{HCC}$ cells
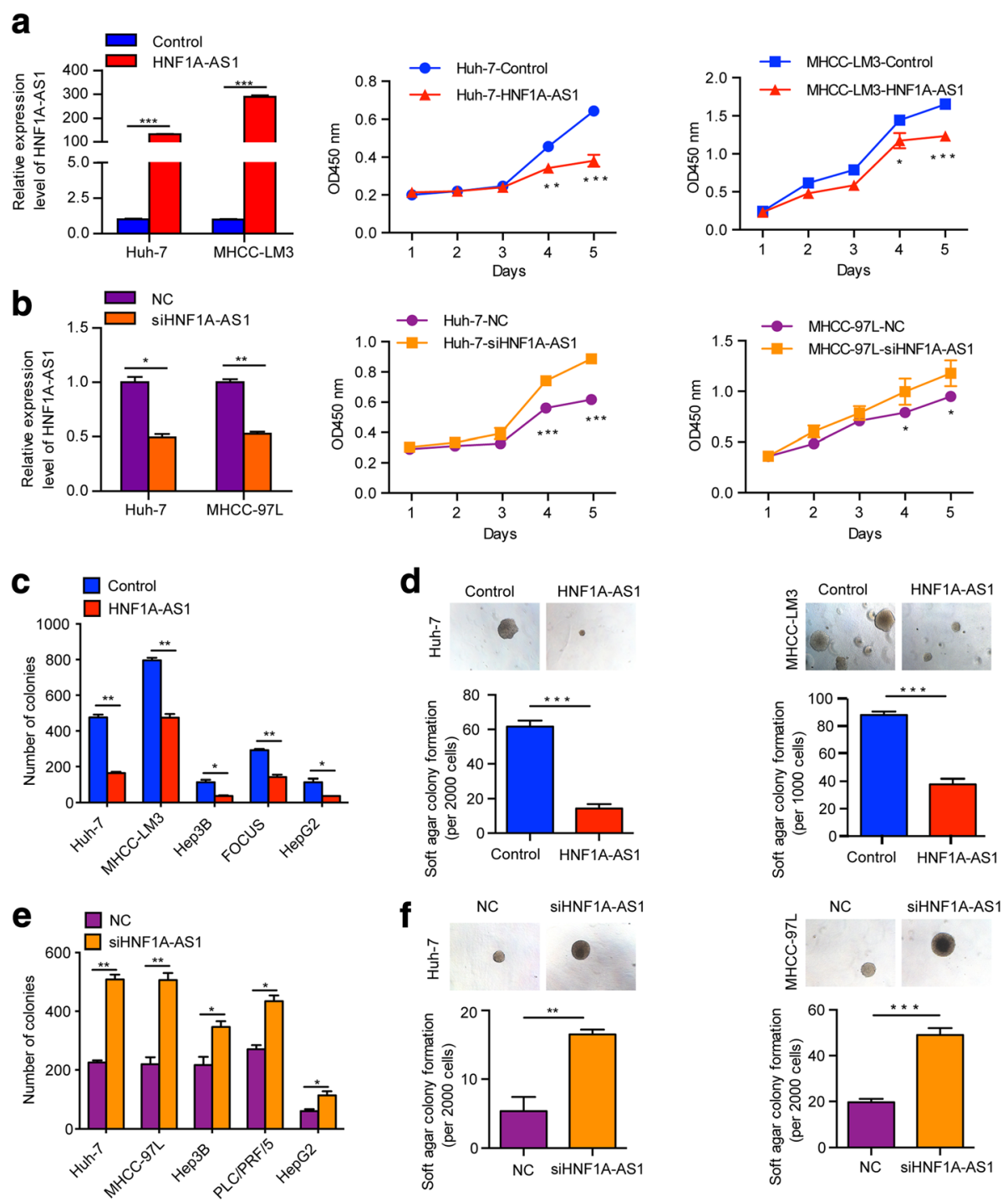

Fig. 3 HNF1A-AS1 suppresses the proliferation and colony formation of HCC cells in vitro. $\mathbf{a}$, $\mathbf{b}$ The expression of HNF1A-AS1 in Huh-7 cells infected with lentivirus (a) or transfected with siRNA (b) were detected by real-time PCR, respectively. Cell proliferation was measured using the Cell Counting Kit-8 (CCK8). (c) Colony formation assays in culture plates were performed with HCC cells infected with lentiviruses. The number of HCC cell colonies with the forced expression of HNF1A-AS1 were counted after 3 weeks. $\mathbf{d}$ Soft agar colony formation assays were performed in HCC cells treated with Lenti-HNF1A-AS1. e, $\mathbf{f}$ Colony formation assays (e) and soft agar colony formation assays ( $\mathbf{f}$ ) were performed in HCC cells transfected with siRNA. Data represent the mean $\pm \mathrm{SD}$ of triplicate experiments. ${ }^{*} P \leq 0.05,{ }^{*} P \leq 0.01$, and ${ }^{* * *} P \leq 0.001$ 
(Fig. 3b and Additional file 1: Figure S3b). Additionally, HNF1A-AS1 overexpression strikingly reduced both anchorage-dependent and independent colony formation of HCC cells while HNF1A-AS1 inhibition exerted the opposite effects (Fig. 3c-f, Additional file 1: Figure S3c and d). Moreover, overexpression of HNF1A-AS1 also significantly diminished the migration and invasion of HCC cells, whereas knockdown of HNF1A-AS1 exacerbated the metastatic potential of these cells (Fig. 4a and b). Furthermore, HNF1A-AS1 knockdown reduced the inhibitory effects of HNF1 $\alpha$ on HCC malignancy (Fig. 4c and d), suggesting that HNF1A-AS1 plays a role in the anti-tumour effect of HNF1 $\alpha$.

\section{HNF1A-AS1 inhibits the tumorigenesis and metastasis of HCC in vivo}

To further validate the effect of HNF1A-AS1 on the tumourigenesis of HCC cells in vivo, we subcutaneously injected Huh-7 cells pre-infected with either LentiHNF1A-AS1 or control virus into the flanks of nude mice. Xenografts were detected on day 21 after injection in all of five mice in the control group, whereas only three mice developed xenografts in the HNF1A-AS1 group at the end of the experiment (day 33). Meanwhile, tumour nodules in the HNF1A-AS1 group were significantly smaller than those in the control group (Fig. 5a). Consistently, the tumour weight was markedly reduced in the HNF1A-AS1 group (Fig. 5b). Real-time PCR confirmed the elevated expression of HNF1A-AS1 in the Lenti-HNF1A-AS1-treated tumours (Fig. 5c). Ki67 staining revealed that HNF1A-AS1 overexpression decreased cell proliferation in the HCC xenografts (Fig. 5d). Similar results were also obtained using MHCC-LM3 cells (Additional file 1: Figure S4a-d).

We next evaluated the effect of HNF1A-AS1 on HCC metastasis in NOD/SCID mice. Luciferase-labelled MHCC-LM3 cells infected with either Lenti-HNF1AAS1 or control virus were injected through the tail veins of mice. These mice were then subjected to in vivo luciferase assays to monitor systemic metastasis once a week for 6 weeks. As indicated by luciferase signals, the overexpression of HNF1A-AS1 markedly inhibited the metastasis of MHCC-LM3 cells in mice, especially bone and abdominal metastases (Fig. 5e). Once the mice were sacrificed, the metastatic tumour nodules in the different organs were further validated based on luciferase signals and HE staining (Additional file 1: Figure S4e). The incidence of lung metastasis was not significantly different in the two groups of mice (5/10 vs. 5/11). However, compared with that in the cells infected with control

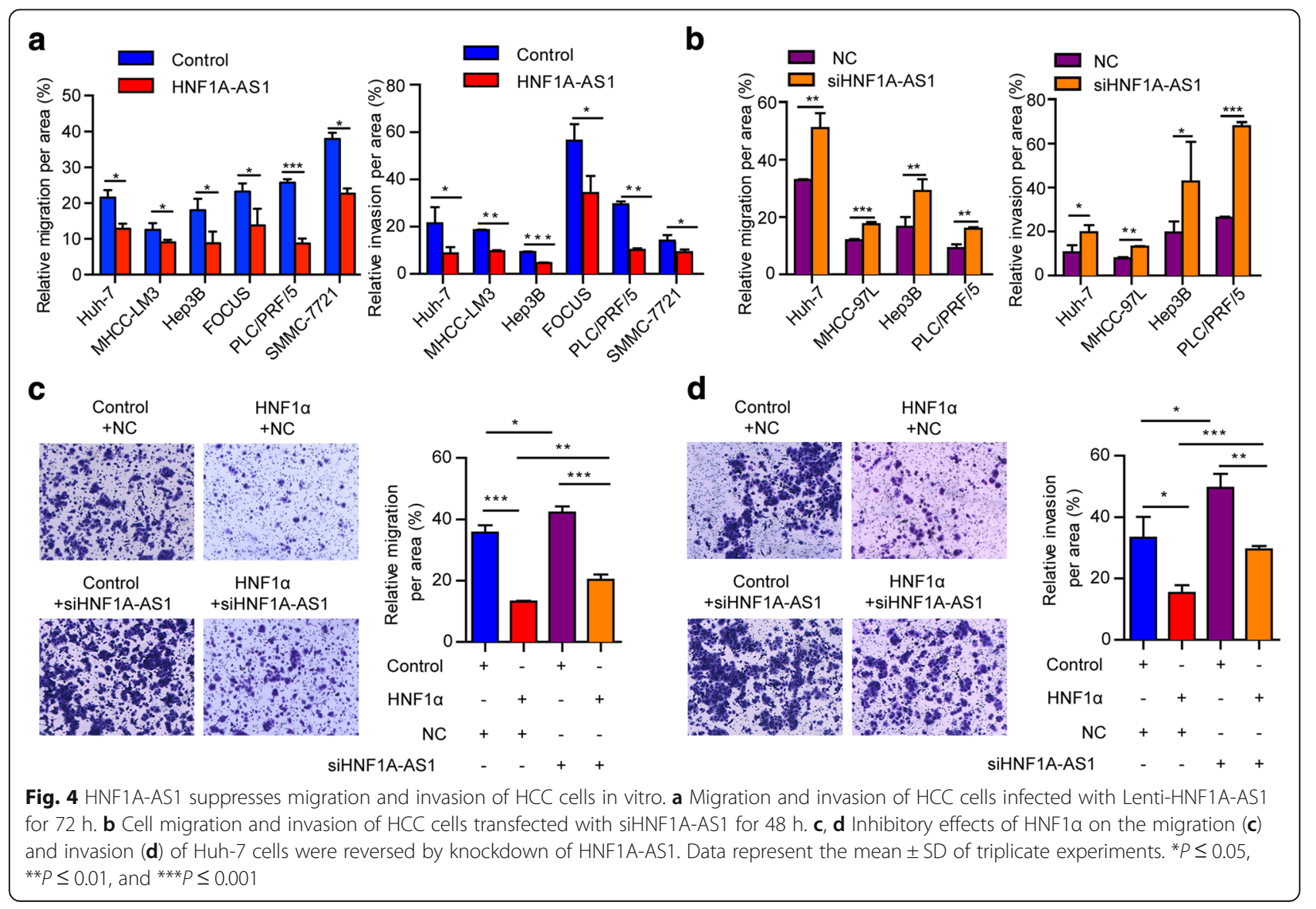




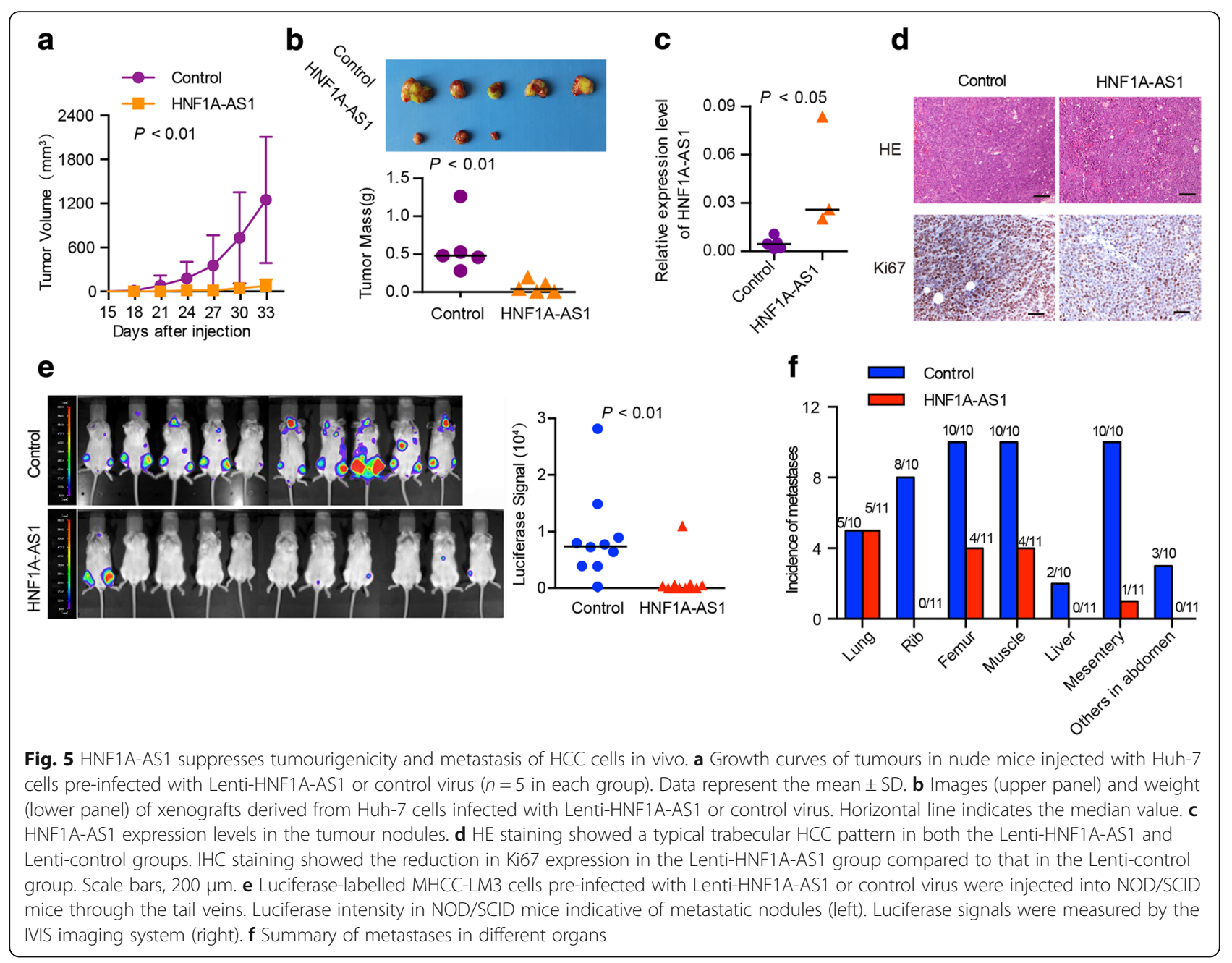

virus, the metastasis of MHCC-LM3 cells infected with Lenti-HNF1A-AS1 to the rib (8/10 vs. $0 / 11)$, femur and muscles $(10 / 10$ vs. $4 / 11)$, liver ( $2 / 10$ vs. $0 / 11)$, mesentery $(10 / 10$ vs. $0 / 11)$ and other abdominal organs such as the pancreas (3/10 vs. 0/11) was markedly inhibited (Fig. 5f).

\section{HNF1A-AS1 directly binds to SHP-1 protein in human HCC cells}

Our previous study has demonstrated the regulation of HNF1 $\alpha$ on SHP-1 expression in rat hepatocytes [22]. In present study, we found that HNF1 $\alpha$ activated HNF1AAS1 expression. Then, we analyzed whether HNF1AAS1 is involved in the regulation of SHP-1 by HNF1 $\alpha$ in human HCC cells. However, we found that neither HNF1 $\alpha$ nor HNF1A-AS1 was significantly correlated with the expression of SHP-1 in human HCC tissues (Additional file 1: Figure $\mathrm{S} 5 \mathrm{a}$ and $\mathrm{b}$ ). In addition, although HNF1 $\alpha$ increased the expression of SHP-1 in primary rat and mouse hepatocytes (Additional file 1: Figure S6a), HNF1 $\alpha$ or HNF1A-AS1 did not alter the levels of SHP-1 in human HCC cells (Additional file 1: Figure S6b and c), suggesting that HNF1 $\alpha$ or HNF1AAS1 could not regulate the expression of SHP-1.

Interestingly, the prediction by RPISeq [27] (http:// pridb.gdcb.iastate.edu/RPISeq/), a database of RNAprotein interactions, suggested a potential interaction of HNF1A-AS1 with the SHP-1 protein with high binding affinity $(\mathrm{RF}=0.7 / \mathrm{SVM}=0.82)$. We then examined the potential interaction of HNF1A-AS1 with SHP-1. RNA pull-down assays showed that HNF1A-AS1 but not its antisense transcript precipitated the SHP-1 protein in Huh-7 cells (Fig. 6a). Moreover, in vitro RNA-protein binding assay revealed that HNF1A-AS1 directly interacted with the recombinant SHP-1 protein (Fig. 6b). RIP experiments confirmed the interaction of SHP-1 with endogenous HNF1A-AS1 in Huh-7 cells (Fig. 6c). To identify the domain of SHP-1 that binds to HNF1A-AS1, truncated SHP-1 protein variants tagged with GST were expressed and purified (Fig. 6d). Protein domain mapping studies demonstrated that HNF1A-AS1 bounds to 

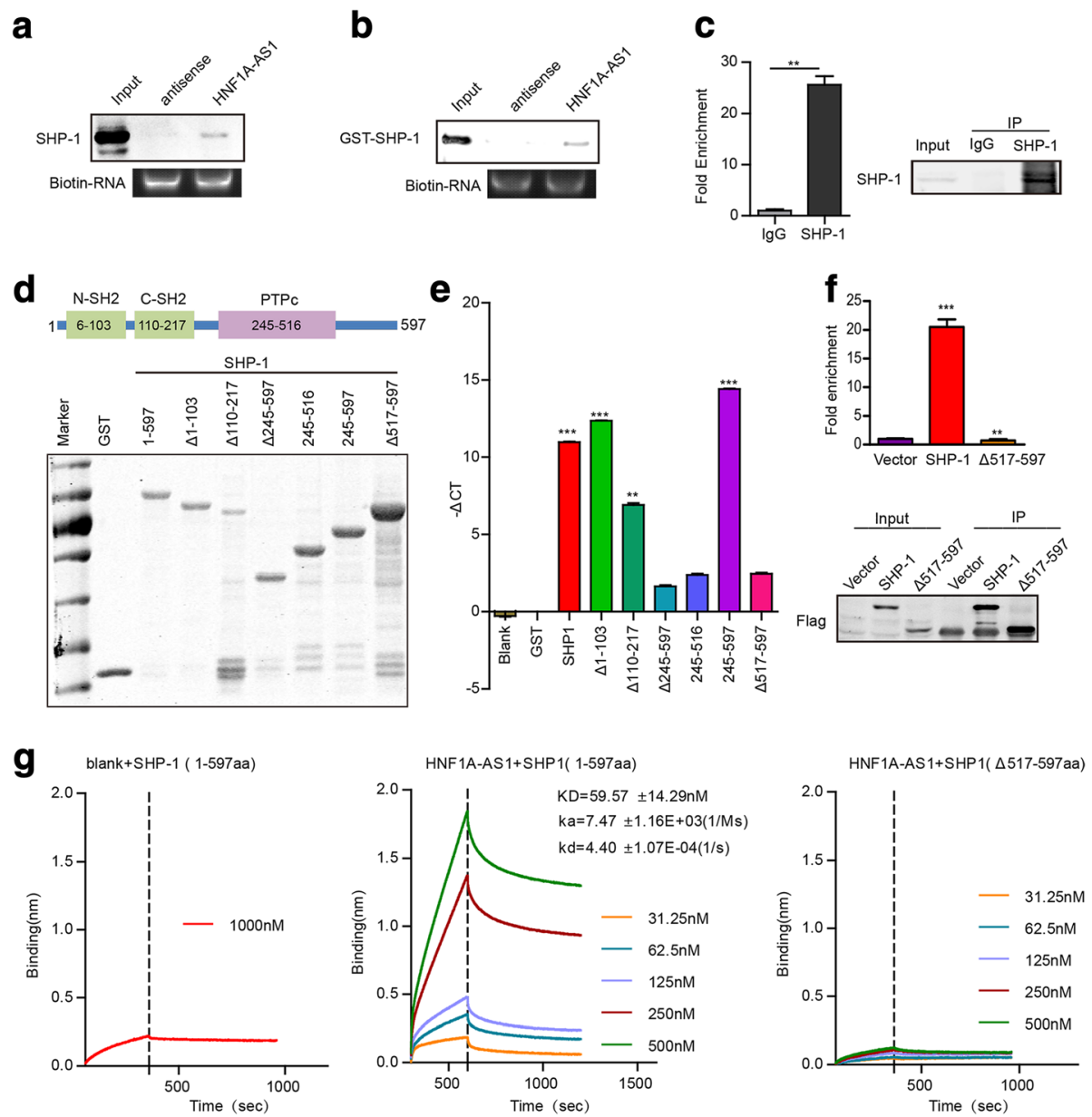

Fig. 6 HNF1A-AS1 directly interacts with SHP-1. a Endogenous SHP-1 protein in Huh-7 cells was precipitated with biotin-labelled HNF1A-AS1 RNA. b RNA pulldown assay showed the direct interaction of HNF1A-AS1 with recombinant SHP-1 protein. c Association of endogenous SHP-1 and HNF1A-AS1 was detected by RIP assay. Huh-7 cell lysates were immunoprecipitated with anti-SHP-1 antibody. Immunoprecipitated HNF1A-AS1 was detected by real-time PCR. RNA from immunoprecipitation reactions with normal rabbit lgG (lgG) was used as the control. $\mathbf{d}$ Deletion mapping of the HNF1A-AS1-binding domain in SHP-1. Upper panel: Graphical illustration of the functional domains of the SHP-1 protein. Lower panel: amount of GST-SHP-1 and domaintruncated SHP-1 variants detected in the binding assay. e Real-time PCR was performed to detect HNF1A-AS1 binding to GST-tagged SHP-1 and domaintruncated SHP-1 variants. $\mathbf{f}$ Huh-7 cells transfected with Flag-SHP-1 or Flag-SHP-1 5 517-597. The endogenous HNF1A-AS1 co-precipitated with Flag-SHP-1 were detected by real-time PCR. Data represent the mean \pm SD of triplicate experiments. ${ }^{*} P \leq 0.01$, and ${ }^{* * *} P \leq 0.001$. g Bio-Layer Interferometry assay showed the binding of HNF1A-AS1 to SHP1 protein with high affinity. Deletion of 517-597 aa abolished the binding of SHP-1 with HNF1A-AS1

the C-terminal (517-597 aa) of the SHP-1 protein (Fig. 6e). In addition, RIP assay also demonstrated that C-terminal deletion abolished the binding of SHP-1 with HNF1A-AS1 in Huh-7 cells (Fig. 6f). Furthermore, BioLayer Interferometry (BLI) assay confirmed the high affinity binding of biotin-labelled HNF1A-AS1 with recombinant SHP-1 protein $(\mathrm{KD}=59.57 \pm 14.29 \mathrm{nM})$, while C-terminal deletion diminished this binding (Fig. 6g).

\section{HNF1A-AS1 inhibits HCC through increasing enzymatic activity of SHP-1}

Previous studies have demonstrated that the C-terminal region of SHP-1 is involved in the regulation of its phosphatase activity $[28,29]$. We then evaluated the effect of HNF1 $\alpha$ and HNF1A-AS1 on SHP-1 activity. Overexpression of either HNF1 $\alpha$ or HNF1A-AS1 significantly increased the enzymatic activity of SHP-1 in Huh-7 cells (Fig. 7a and b). In addition, HNF1A-AS1 knockdown blocked HNF1 $\alpha$-induced SHP-1 activation (Fig. 7c), indicating that HNF1 $\alpha$ regulates SHP-1 activity through HNF1A-AS1. Moreover, in vitro phosphatase assay showed that HNF1A-AS1 also enhanced the tyrosine phosphatase activity of recombinant SHP-1, which was abolished by the deletion of the SHP-1 C-terminal (Fig. 7d). These results suggested that HNF1A-AS1 increased SHP-1 activity through direct interaction with SHP-1. Furthermore, inhibition of SHP-1 activity using 


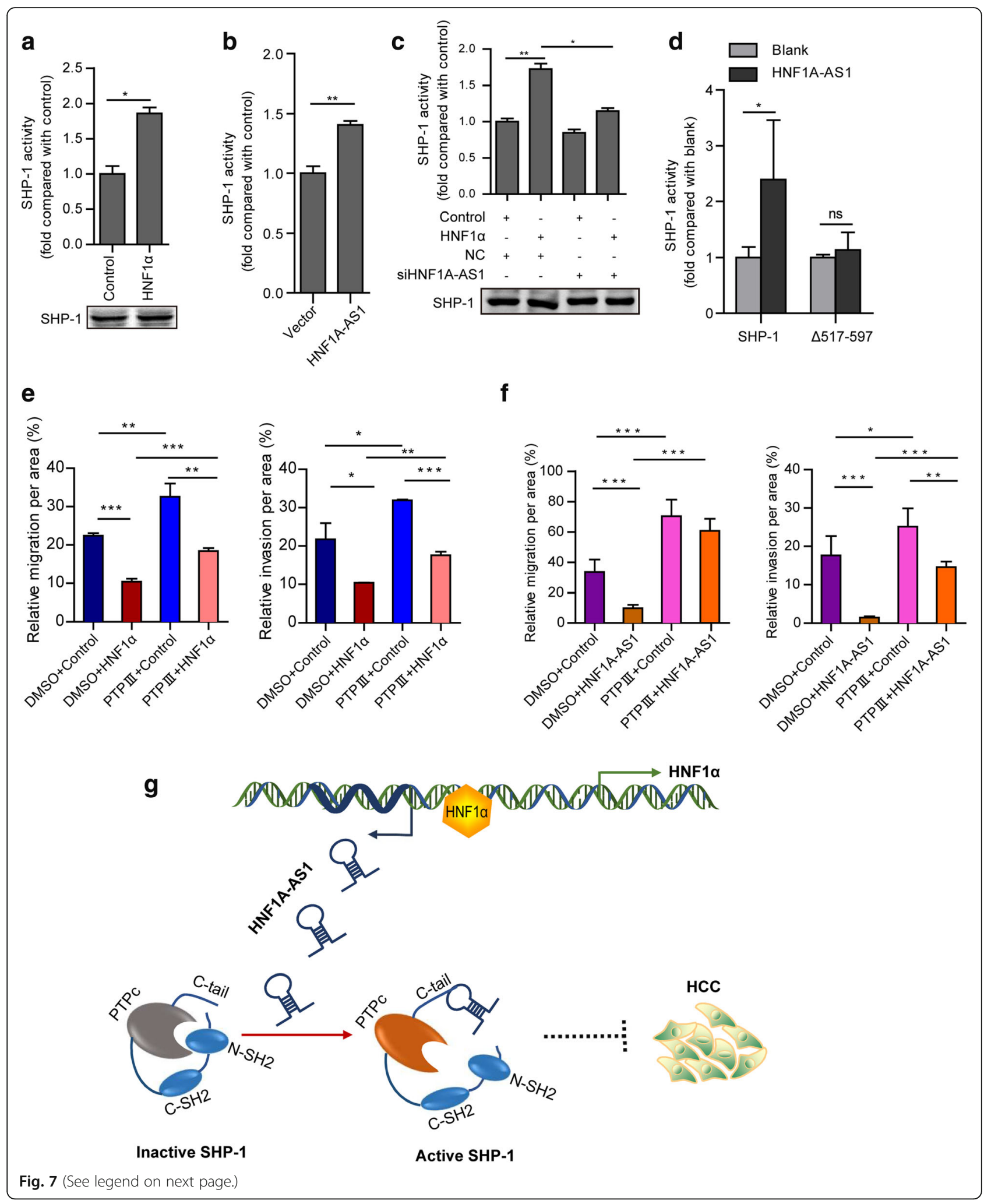


(See figure on previous page.)

Fig. 7 HNF1A-AS1 increases the phosphatase activity of SHP-1 by interacting with the C-terminal of SHP-1. a Overexpression of HNF1a increased the phosphatase activity of SHP-1 in Huh-7 cells. The amount of SHP-1 protein used for the phosphatase assay were detected by western blotting (lower panel). $\mathbf{b}$ HNF1A-AS1 enhanced the phosphatase activity of SHP-1 in Huh-7 cells. c Forced expression of HNF1a induced phosphatase activity of SHP-1 activation, while knockdown of HNF1A-AS1 blocked the effect of HNF1a on SHP-1. $\mathbf{d}$ HNF1A-AS1 increased the phosphatase activity of the recombinant SHP-1 protein in vitro. C-terminal deletion of SHP-1 abolished the effect of HNF1A-AS1. e, $\mathbf{f}$ The specific phosphatase inhibitor of SHP-1, PTP inhibitor III (PTP III), reverse the inhibitory effect of HNF1a (e) or HNF1A-AS1 (f) on the migration and invasion of Huh-7 cells. Data represent the mean \pm SD of triplicate experiments. ${ }^{*} P \leq 0.05,{ }^{*} P \leq 0.01$, and ${ }^{* * *} P \leq 0.001 . \mathbf{g}$ A schematic model representing that HNF1a increases the activity of SHP-1 in human HCC cells via upregulating HNF1A-AS1

protein tyrosine phosphatase inhibitor III (PTP inhibitor III) substantially reversed HNF1 $\alpha$ - or HNF1A-AS1induced reduction in the migration and invasion of Huh-7 cells (Fig. 7e and f). Taken together, these data suggested that the activation of SHP-1 were involved in the anti-tumour effects of HNF1 $\alpha$ and HNF1A-AS1.

\section{Discussion}

It has been reported that HNF1A-AS1 is a poorly conserved lncRNA that is highly expressed in the liver, gastrointestinal track and kidney in human [30]. According to the NCBI database, HNF1A-AS1 is transcribed from a 2455-nucleotide single-exon gene. In this study, we validated the sequence of HNF1A-AS1 with RACE and northern blotting and revealed that full-length HNF1A-AS1 is 2785 nt long with poly A tail structure in human liver tissues. We also demonstrated that being an adjacent lncRNA to the HNF1 $\alpha$ gene, HNF1A-AS1 is transcriptionally regulated by $\mathrm{HNF} 1 \alpha$, which is consistent with previous findings that lncRNAs are frequently regulated by their neighbouring protein-coding genes [31].

As an emerging lncRNA, the function of HNF1A-AS1 in tumours was far from being well understood. HNF1A-AS1 was upregulated in oesophageal, lung, bladder and colon cancers, and osteosarcoma but downregulated in gastric and pancreatic cancers [30, 32-37]. These contradictory results imply a tissue-specific role of HNF1A-AS1. Recently, two reports indicated that HNF1A-AS1 promoted the proliferation of HCC cells by sponging hsa-miR- 30b-5p to promote autophagy or by repressing the NKD1 and p21 via binding to EZH2 [38, 39]. However, the above studies did not characterize the full-length of HNF1A-AS1. Furthermore, the effect of HNF1A-AS1 on the metastatic property of $\mathrm{HCC}$ in vitro and malignancy in vivo was not reported in these papers. Therefore, the regulatory function of full-length HNF1A-AS1 in HCC still needs to be further investigated.

HNF1 $\alpha$ has been found to play a tumour suppressor role in HCC. In this study, we found that patients with high HNF1 $\alpha$ protein levels displayed superior overall survival (OS) by using an HCC tissue microarray containing 277 patients (median OS 42 and 33 months, respectively, $P=0.012$; Additional file 1 , Figure $\mathrm{S} 7$ ). The expression of HNF1A-AS1 was positively correlated with the expression of HNF1 $\alpha$ in HCC tissues, implying HNF1A-AS1 may also have anti-tumour effect in HCC. In addition, our data also clearly demonstrated that the upregulation of full-length HNF1A-AS1 suppressed the proliferative and metastatic behaviours of $\mathrm{HCC}$ cells both in vitro and in vivo. Moreover, the knockdown of HNF1A-AS1 significantly promoted HCC malignant properties and reversed the inhibitory effects of HNF1 $\alpha$ on HCC. These findings suggest that HNF1A-AS1 indeed acts as a tumour suppressor rather than an oncogene in $\mathrm{HCC}$ progression and partially mediates the anti-HCC effects of HNF1 $\alpha$.

It has been demonstrated that IncRNAs exert their functions by interacting with chromatin DNA, mRNAs or proteins to regulate chromatin accessibility, mRNA stability and protein activity or stability, respectively [40, 41]. Interestingly, several studies have reported that lncRNAs are also involved in the regulation of protein phosphorylation. The lncRNA BCAR4 has been reported to recruit PNUTS, a negative regulatory subunit of PP1, to H3K18ac and relieve the inhibition of RNA Pol II via the activation of the PP1 phosphatase [42]. The lncRNA NKILA has been shown to inhibit IkB phosphorylation by interacting with the NF- $\mathrm{B}: \mathrm{I} \kappa \mathrm{B}$ complex [43]. A recent study revealed that IncRNA TSLNC8 competitively interacted with transketolase (TKT) and STAT3 and modulated the phosphorylation of STAT3-Tyr705 and STAT3-Ser727 in HCC cells [44]. However, whether lncRNAs can directly regulate phosphatase activity has not been reported before. Here, we demonstrated that HNF1A-AS1 enhanced the activity of SHP-1 by directly binding to the C-terminal of the SHP-1 protein. Inhibition of the phosphatase activity of SHP-1 reversed the suppression of cellular migration and invasion induced by HNF1 $\alpha$ and HNF1A-AS1. These data suggest that the increased enzymatic activity of SHP-1 contributes to the anti-tumour effects of HNF1 $\alpha$ and HNF1A-AS1.

It is known that the expression of lncRNAs is strikingly cell type and tissue specific and in many cases, even primate specific $[45,46]$. BLAST analysis using the NCBI database revealed that the HNF1A-AS1 transcript is primate-specific. No transcripts of HNF1A-AS1 have been detected in rodents to date. As a consequence of 
this species-specific expression pattern, we documented that HNF1 $\alpha$ directly regulated SHP-1 expression in rodents such as mice and rats, while increased the activity of SHP-1 in human HCC cells via upregulating HNF1AAS1. Thus, we proposed that HNF1A-AS1 orchestrated the regulatory effect of HNF1 $\alpha$ on SHP-1 in a more delicate and complex manner in human cells (Fig. 7g).

\section{Conclusion}

In conclusion, this study revealed that the full length of HNF1A-AS1 is $2785 \mathrm{nt}$, which is $330 \mathrm{bp}$ longer than the previous reported sequence. HNF1A-AS1 is directly transcriptional regulated by $\mathrm{HNF} 1 \alpha$ and mediates the anti-HCC effect of HNF1 $\alpha$ in HCC cells. Moreover, we reported that HNF1A-AS1 exerts its suppressor role of HCC via interacting with SHP-1 as an enzyme activator, which extends our knowledge regarding the function of lncRNAs. These findings may imply that manipulation of HNF1A-AS1 expression might have therapeutic effects against HCC.

\section{Additional files}

Additional file 1: Figure S1. Identification of HNF1a-regulated IncRNAs. Figure S2. HNF1 a directly binds to the promoter region of HNF1A-AS1. Figure S3. HNF1A-AS1 suppresses the malignancy of HCC cells. Figure S4. Enforced expression of HNF1A-AS1 suppresses tumourigenicity and metastasis of MHCC-LM3 cells. Figure S5. The correlation analysis between the expression levels of SHP-1 and HNF1a or HNF1A-AS1 levels in human HCC tissues. Figure S6. HNF1 $\mathrm{a}$ and HNF1A-AS1 do not regulate the expression of SHP-1 in human HCC cells. Figure S7. Reduction of HNF1a predicts poor prognosis of patients. Table S1. Oligonucleotides used in real-time PCR, cloning and knockdown studies. Primer sequences for real-time PCR. Table S3. Binding motif of IncRNA promoter regions for HNF1a RE. (PDF $2800 \mathrm{~kb})$ (PDF $15484 \mathrm{~kb}$ )

Additional file 2: Table S2. Fifty-one annotated IncRNAs upregulated by HNF1a. (XLSX $16 \mathrm{~kb})$

\section{Abbreviations}

ChIP: Chromatin immunoprecipitation; HCC: Hepatocellular carcinoma; HE: hematoxylin and eosin; HNF1A-AS1: HNF1A antisense RNA 1; HNF1a: Hepatocyte nuclear factor 1a; IncRNAs: Long non-coding RNAs; RIP: RNA-binding protein immunoprecipitation; SHP-1: SH2 domaincontaining tyrosine phosphatase-1

\section{Acknowledgments}

We thank Dr. Jin Ding and Dr. Pin Wang for technical support.

\section{Funding}

This work was supported by the National Natural Science Foundation of China (81572377 and 81772523 to X.Z., 81602041 to J.W, 81230011 and 81530019 to W.F.X., and 81625022 and 81430084 to C.L.).

\section{Availability of data and materials}

The dataset of IncRNA microarray is available at NCBI Gene Expression Omnibus (http://www.ncbi.nlm.nih.gov/geo/) under the accession number GSE103128.

\section{Authors' contributions}

$X Z, W F X$ and $\mathrm{CL}$ designed the study; CHD, CY and SJL performed the experiments for the regulation of HNF1a on HNF1A-AS1 and the effect of HNF1A-AS1 on HCC; CHD, SJC, KD and JPL validated the interaction of HNF1A-AS1 and SHP-1; LZW and KD performed the experiment for the enzymatic experiment of SHP-1; JW,
$X Z$, CL, and WFX provided the founding; $K X C$ and $H \sqcup$ provided reagents and instrumentations; CHD, CY and LZW wrote the original draft; XZ, CL, and WFX revised and edited the manuscript; $C L$ and WFX supervised the entire study. All authors read and approved the final manuscript.

\section{Ethics approval}

All animal experiments were performed in accordance with protocols approved by the Institutional Animal Care and Use Committee at the Second Military Medical University, Shanghai, China. Clinical human HCC samples were obtained from HCC patients undergoing surgical resection at the Eastern Hepatobiliary Surgery Hospital (Shanghai, China). Written informed consent was obtained from all patients. And all human experiments were approved by the Ethics Committee of the Second Military Medical University, Shanghai, China.

\section{Consent for publication}

Not applicable.

\section{Competing interests}

The authors declare no conflicts of interest.

\section{Publisher's Note}

Springer Nature remains neutral with regard to jurisdictional claims in published maps and institutional affiliations.

\section{Author details}

'Department of Gastroenterology, Changzheng Hospital, Second Military Medical University, 415 Fengyang Road, Shanghai 200003, China. ${ }^{2}$ Drug Discovery and Design Center, CAS Key Laboratory of Receptor Research, State Key Laboratory of Drug Research, Shanghai Institute of Materia Medica, Chinese Academy of Sciences (CAS), Shanghai 201203, China. ${ }^{3}$ Present address: Department of Gastroenterology, Institute of Surgery Research, Daping Hospital, Third Military Medical University, Chongqing 400042, China.

Received: 16 November 2017 Accepted: 8 February 2018

Published online: 21 February 2018

\section{References}

1. Jemal A, Bray F, Center MM, Ferlay J, Ward E, Forman D. Global cancer statistics. CA Cancer J Clin. 2011;61:69-90.

2. Huarte M. The emerging role of IncRNAs in cancer. Nat Med. 2015;21:1253-61.

3. Klingenberg M, Matsuda A, Diederichs S, Patel T. Non-coding RNA in hepatocellular carcinoma: mechanisms, biomarkers and therapeutic targets. J Hepatol. 2017;67:603-18.

4. Li L, Chang HY. Physiological roles of long noncoding RNAs: insight from knockout mice. Trends Cell Biol. 2014;24:594-602.

5. Quinn JJ, Chang HY. Unique features of long non-coding RNA biogenesis and function. Nat Rev Genet. 2016;17:47-62.

6. Odom DT, Zizlsperger N, Gordon DB, Bell GW, Rinaldi NJ, Murray HL, Volkert TL, Schreiber J, Rolfe PA, Gifford DK, et al. Control of pancreas and liver gene expression by HNF transcription factors. Science. 2004:303:1378-81.

7. Shih DQ, Bussen M, Sehayek E, Ananthanarayanan M, Shneider BL, Suchy FJ, Shefer S, Bollileni JS, Gonzalez FJ, Breslow JL, Stoffel M. Hepatocyte nuclear factor-1alpha is an essential regulator of bile acid and plasma cholesterol metabolism. Nat Genet. 2001;27:375-82.

8. Costa RH, Kalinichenko W, Holterman AX, Wang X. Transcription factors in liver development, differentiation, and regeneration. Hepatology. 2003;38:1331-47.

9. Zeng X, Lin Y, Yin C, Zhang X, Ning BF, Zhang Q, Zhang JP, Qiu L, Qin XR, Chen YX, Xie WF. Recombinant adenovirus carrying the hepatocyte nuclear factor-1alpha gene inhibits hepatocellular carcinoma xenograft growth in mice. Hepatology. 2011;54:2036-47.

10. Ni Q, Ding K, Wang KQ, He J, Yin C, Shi J, Zhang X, Xie WF, Shi YQ. Deletion of HNF1alpha in hepatocytes results in fatty liver-related hepatocellular carcinoma in mice. FEBS Lett. 2017:591:1947-57.

11. Krutzfeldt J, Rosch N, Hausser J, Manoharan M, Zavolan M, Stoffel M. MicroRNA-194 is a target of transcription factor 1 (Tcf1, HNF1alpha) in adult liver and controls expression of frizzled-6. Hepatology. 2012;55:98-107.

12. Bao C, Li Y, Huan L, Zhang Y, Zhao F, Wang Q, Liang L, Ding J, Liu L, Chen T, et al. NF-kappaB signaling relieves negative regulation by miR-194 in 
hepatocellular carcinoma by suppressing the transcription factor HNF1alpha. Sci Signal. 2015;8:ra75.

13. Tsui FW, Martin A, Wang J, Tsui HW. Investigations into the regulation and function of the SH2 domain-containing protein-tyrosine phosphatase, SHP1. Immunol Res. 2006;35:127-36.

14. Lopez-Ruiz P, Rodriguez-Ubreva J, Cariaga AE, Cortes MA, Colas B. SHP-1 in cell-cycle regulation. Anti Cancer Agents Med Chem. 2011;11:89-98.

15. Xu E, Charbonneau A, Rolland Y, Bellmann K, Pao L, Siminovitch KA, Neel BG, Beauchemin N, Marette A. Hepatocyte-specific Ptpn6 deletion protects from obesity-linked hepatic insulin resistance. Diabetes. 2012;61:1949-58.

16. Xu E, Forest MP, Schwab M, Avramoglu RK, St-Amand E, Caron AZ, Bellmann K, Shum M, Voisin G, Paquet M, et al. Hepatocyte-specific Ptpn6 deletion promotes hepatic lipid accretion, but reduces NAFLD in diet-induced obesity: potential role of PPARgamma. Hepatology. 2014;59:1803-15.

17. Dubois MJ, Bergeron S, Kim HJ, Dombrowski L, Perreault M, Fournes B, Faure R, Olivier M, Beauchemin N, Shulman Gl, et al. The SHP-1 protein tyrosine phosphatase negatively modulates glucose homeostasis. Nat Med. 2006;12:549-56.

18. Tai WT, Cheng AL, Shiau CW, Liu CY, Ko CH, Lin MW, Chen PJ, Chen KF. Dovitinib induces apoptosis and overcomes sorafenib resistance in hepatocellular carcinoma through SHP-1-mediated inhibition of STAT3. Mol Cancer Ther. 2012;11:452-63.

19. Chen KF, Su JC, Liu CY, Huang JW, Chen KC, Chen WL, Tai WT, Shiau CW. A novel obatoclax derivative, SC-2001, induces apoptosis in hepatocellular carcinoma cells through SHP-1-dependent STAT3 inactivation. Cancer Lett. 2012;321:27-35

20. Chen KF, Tai WT, Hsu CY, Huang JW, Liu CY, Chen PJ, Kim I, Shiau CW. Blockade of STAT3 activation by sorafenib derivatives through enhancing SHP-1 phosphatase activity. Eur J Med Chem. 2012;55:220-7.

21. Fan LC, Shiau CW, Tai WT, Hung MH, Chu PY, Hsieh FS, Lin H, Yu HC, Chen KF. SHP-1 is a negative regulator of epithelial-mesenchymal transition in hepatocellular carcinoma. Oncogene. 2015;34:5252-63.

22. Qian $H$, Deng $X$, Huang ZW, Wei J, Ding CH, Feng RX, Zeng $X$, Chen $Y X$, Ding J, Qiu L, et al. An HNF1alpha-regulated feedback circuit modulates hepatic fibrogenesis via the crosstalk between hepatocytes and hepatic stellate cells. Cell Res. 2015;25:930-45.

23. Yin $C$, Wang $P Q$, Xu WP, Yang Y, Zhang Q, Ning BF, Zhang PP, Zhou WP, Xie WF, Chen WS, Zhang X. Hepatocyte nuclear factor-4alpha reverses malignancy of hepatocellular carcinoma through regulating miR-134 in the DLK1-DIO3 region. Hepatology. 2013;58:1964-76.

24. Xu WP, Yi M, Li QQ, Zhou WP, Cong WM, Yang Y, Ning BF, Yin C, Huang ZW, Wang J, et al. Perturbation of MicroRNA-370/Lin-28 homolog a/nuclear factor kappa B regulatory circuit contributes to the development of hepatocellular carcinoma. Hepatology. 2013;58:1977-91.

25. Liu J, Chen S, Wang W, Ning BF, Chen F, Shen W, Ding J, Chen W, Xie WF, Zhang X. Cancer-associated fibroblasts promote hepatocellular carcinoma metastasis through chemokine-activated hedgehog and TGF-beta pathways. Cancer Lett. 2016;379:49-59.

26. Bryne JC, Valen E, Tang MH, Marstrand T, Winther O, da Piedade I, Krogh A, Lenhard B, Sandelin A. JASPAR, the open access database of transcription factor-binding profiles: new content and tools in the 2008 update. Nucleic Acids Res. 2008;36:D102-6.

27. Muppirala UK, Honavar VG, Dobbs D. Predicting RNA-protein interactions using only sequence information. BMC Bioinformatics. 2011;12:489.

28. Jones ML, Craik JD, Gibbins JM, Poole AW. Regulation of SHP-1 tyrosine phosphatase in human platelets by serine phosphorylation at its C terminus. J Biol Chem. 2004;279:40475-83.

29. Liu Y, Kruhlak MJ, Hao JJ, Shaw S. Rapid T cell receptor-mediated SHP-1 S591 phosphorylation regulates SHP-1 cellular localization and phosphatase activity. J Leukoc Biol. 2007;82:742-51.

30. Yang X, Song JH, Cheng Y, Wu W, Bhagat T, Yu Y, Abraham JM, lbrahim S, Ravich W, Roland BC, et al. Long non-coding RNA HNF1A-AS1 regulates proliferation and migration in oesophageal adenocarcinoma cells. Gut. 2014;63:881-90.

31. Rinn JL, Chang HY. Genome regulation by long noncoding RNAs. Annu Rev Biochem. 2012;81:145-66.

32. Wu Y, Liu H, Shi X, Yao Y, Yang W, Song Y. The long non-coding RNA HNF1A-AS1 regulates proliferation and metastasis in lung adenocarcinoma. Oncotarget. 2015;6:9160-72.

33. Cai L, LV J, Zhang Y, Li J, Wang Y, Yang H. The IncRNA HNF1A-AS1 is a negative prognostic factor and promotes tumorigenesis in osteosarcoma. J. Cell Mol Med. 2017;
34. Dang $Y$, Lan F, Ouyang $X$, Wang $K$, Lin $Y$, Yu Y, Wang L, Wang Y, Huang $Q$. Expression and clinical significance of long non-coding RNA HNF1A-AS1 in human gastric cancer. World J Surg Oncol. 2015;13:302.

35. Zhan Y, Li Y, Guan B, Wang Z, Peng D, Chen Z, He A, He S, Gong Y, Li X, Zhou L. Long non-coding RNA HNF1A-AS1 promotes proliferation and suppresses apoptosis of bladder cancer cells through upregulating BCl-2. Oncotarget. 2017;8:76656-65.

36. Fang C, Qiu S, Sun F, Li W, Wang Z, Yue B, Wu X, Yan D. Long non-coding RNA HNF1A-AS1 mediated repression of miR-34a/SIRT1/p53 feedback loop promotes the metastatic progression of colon cancer by functioning as a competing endogenous RNA. Cancer Lett. 2017:410:50-62.

37. Muller $S$, Raulefs $S$, Bruns $P$, Afonso-Grunz F, Plotner A, Thermann R, Jager $C$, Schlitter AM, Kong B, Regel I, et al. Next-generation sequencing reveals novel differentially regulated mRNAs, IncRNAs, miRNAs, sdRNAs and a piRNA in pancreatic cancer. Mol Cancer. 2015;14:94.

38. Wang C, Mou L, Chai HX, Wang F, Yin YZ, Zhang XY. Long non-coding RNA HNF1A-AS1 promotes hepatocellular carcinoma cell proliferation by repressing NKD1 and P21 expression. Biomed Pharmacother. 2017;89:926-32.

39. Liu Z, Wei X, Zhang A, Li C, Bai J, Dong J. Long non-coding RNA HNF1AAS1 functioned as an oncogene and autophagy promoter in hepatocellular carcinoma through sponging hsa-miR-30b-5p. Biochem Biophys Res Commun. 2016:473:1268-75.

40. Lau E. Non-coding RNA: zooming in on IncRNA functions. Nat Rev Genet. 2014;15:574-5.

41. Guttman M, Rinn JL. Modular regulatory principles of large non-coding RNAs. Nature. 2012:482:339-46.

42. Xing Z, Lin A, Li C, Liang K, Wang S, Liu Y, Park P, Qin L, Wei Y. Hawke D, et al: IncRNA directs cooperative epigenetic regulation downstream of chemokine signals. Cell. 2014;159:1110-25.

43. Liu B, Sun L, Liu Q, Gong C, Yao Y, Lv X, Lin L, Yao H, Su F, Li D, et al. A cytoplasmic NF-kappaB interacting long noncoding RNA blocks IkappaB phosphorylation and suppresses breast cancer metastasis. Cancer Cell. 2015; 27:370-81.

44. Zhang J, Li Z, Liu L, Wang Q, Li S, Chen D, Hu Z, Yu T, Ding J, Li J, et al: Long noncoding RNA TSLNC8 is a tumor suppressor that inactivates the interleukin-6/STAT3 signaling pathway. Hepatology. 2018;67:171-87.

45. Hu X, Feng Y, Zhang D, Zhao SD, Hu Z, Greshock J, Zhang Y, Yang L, Zhong $X$, Wang LP, et al. A functional genomic approach identifies FAL1 as an oncogenic long noncoding RNA that associates with BMI1 and represses p21 expression in cancer. Cancer Cell. 2014;26:344-57.

46. Ulitsky I. Bartel DP: lincRNAs: genomics, evolution, and mechanisms. Cell. 2013:154:26-46.

\section{Submit your next manuscript to BioMed Central and we will help you at every step:}

- We accept pre-submission inquiries

- Our selector tool helps you to find the most relevant journal

- We provide round the clock customer support

- Convenient online submission

- Thorough peer review

- Inclusion in PubMed and all major indexing services

- Maximum visibility for your research

Submit your manuscript at www.biomedcentral.com/submit
Biomed Central 